\title{
Úlcera de córnea bilateral por Pseudomonas em usuário de lente de contato descartável
}

\author{
Bilateral Pseudomonas corneal ulcer in a disposable contact lens wearer
}

César Lipener ${ }^{(1)}$

André Luiz Parolin Ribeiro ${ }^{(2)}$

\section{RESUMO}

Introdução: Apesar da sua aparente simplicidade, o uso de lentes descartáveis deve ser feito respeitando-se os critérios de forma de uso, conservação e descarte. A úlcera de córnea bacteriana é a complicação mais temida em usuários de lente e pode ter relação com vários fatores tais como higiene, conservação e principalmente o uso prolongado.

Objetivo: Descrever um caso de úlcera bilateral por Pseudomonas em um paciente usuário de lentes descartáveis, evidenciando e discutindo a importância do exame prévio, orientação e seguimento adequados, bem como ressaltando que por ser descartável a lente não é isenta de complicações graves.

Relato do caso: Um estudante de 17 anos, usando lentes descartáveis há 6 meses, sem exame ou prescrição médica, nos procurou queixandose de dor em OE no qual observou-se úlcera corneana infiltrada na meia periferia. Foi colhido material e iniciado tratamento com colírios fortificados. Após 8 horas, retornou referindo agora dor em OD, tendo sido observada ceratite difusa com secreção mucopurulenta. A conduta foi a mesma. Os exames revelaram Pseudomonas em ambos os olhos e o quadro regrediu sem seqüelas após uma semana de tratamento.

Discussão: $\mathrm{O}$ autor discute os principais fatores envolvidos com o aparecimento de ceratite infecciosa em usuários de lentes de contato, lembrando que as lentes descartáveis, apesar da sua aparente simplicidade também estão relacionadas com este grave quadro. Ressalta ainda que o uso prolongado é considerado um dos seus principais fatores de risco. $O$ relato de um caso de ceratite bilateral serve de alerta para o uso deste tipo de lente sem a devida orientação e acompanhamento.

Palavras-chave: Úlcera de córnea; Lente de contato: descartável, bilateral.
Trabalho realizado no Setor de Lentes de Contato da Universidade Federal de São Paulo.

Mestre em Oftalmologia e membro do Setor de Lentes de Contato da Universidade Federal de São Paulo (UNIFESP/EPM).

(2) Residente de primeiro ano da UNIFESP/EPM.

Endereço para correspondência: R. Manoel da Nóbrega, 595 conj. 91. São Paulo (SP) - Brasil. CEP 04001-083

\section{INTRODUÇÃ̃O}

O uso de lentes de contato para correção das ametropias vem sendo empregado largamente na prática oftalmológica com excelentes resultados.

Existem vários tipos de lentes de contato e dentre eles destaca-se atualmente o grupo das descartáveis, tanto para uso diário como para uso prolongado. Assim como as lentes RGP e gelatinosas convencionais, este tipo de lente de contato têm particularidades quanto à sua forma de uso, conservação e manuseio.

O usuário de LC deve seguir corretamente e com regularidade as instruções do seu oftalmologista bem como respeitar o período de descarte sugerido pelo fabricante a fim de se evitar complicações, como por exemplo ceratites, deformidade corneana, isquemia limbar, infiltrados corneanos estéreis e infecciosos. 
A úlcera de córnea bacteriana é a complicação mais grave e mais temida, podendo levar às seqüelas permanentes. Vários fatores são considerados de risco para seu aparecimento, tais como má higiene, conservação e manutenção inadequadas e principalmente o uso prolongado. Em estudo realizado na Suécia, Swen e cols. concluiu que o uso prolongado de lentes convencionais ou descartáveis aumenta de maneira significativa o risco de complicações graves e que necessitem de hospitalização ${ }^{1}$.

\section{RELATO DO CASO}

Um estudante de 17 anos de idade nos procurou queixando-se de dor no olho esquerdo há um dia. Referia estar usando lentes descartáveis há 6 meses, adquiridas no comércio, sem prescrição médica ou exame ocular prévio. Foi recomendado uso prolongado (dormir com lentes) por até 15 dias ou uso diário por até um mês, com a orientação de usar uma solução multi-uso.

Ao exame, apresentava uma úlcera corneana de $2 \mathrm{~mm}$ na meia periferia superior do olho esquerdo (Figura 1), com infiltrado ao redor e secreção muco-purulenta. O olho direito não apresentava nenhuma alteração neste momento. Foi realizada cultura da úlcera e iniciado tratamento com Cefalotina $50 \mathrm{mg} / \mathrm{ml}$ e Gentamicina $14 \mathrm{mg} / \mathrm{ml}$ alternados a cada 30 minutos. Cerca de 8 horas depois, o paciente retornou queixando-se de dor no olho direito. Ao exame notava-se hiperemia, ceratite difusa e secreção muco purulenta. Foi novamente colhido material para exame e iniciado o mesmo tratamento instituído para o olho esquerdo. Os exames detectaram Pseudomonas em ambos os olhos, resistentes a cefalotina e sensíveis à gentamicina. Diante destes achados, o paciente permaneceu usando o aminoglicosídeo e após uma semana de tratamento, a ceratite regrediu nos 2 olhos, felizmente sem seqüelas visuais importantes.

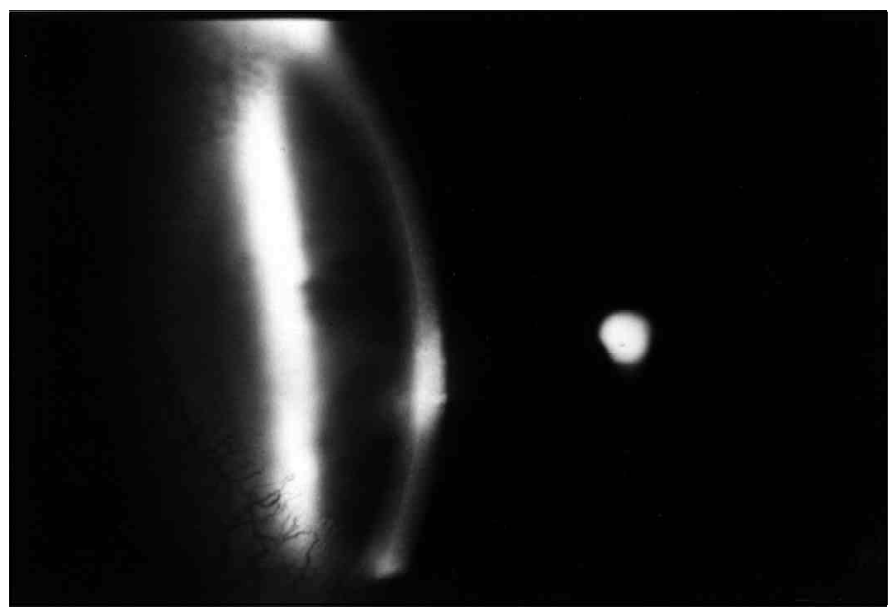

Fig. 1 - Úlcera de córnea no olho esquerdo

\section{DISCUSSÃO}

O agente etiológico mais freqüente nas úlceras de córnea bacterianas em usuários de lentes de contato é a Pseudomonas. A sua evolução é geralmente rápida, podendo causar baixa de visão permanente ${ }^{2,3}$.

Estudos mostram que os infiltrados corneanos podem estar relacionados com conservação, limpeza e desinfecção inadequados das LC pelos usuários. Kampolat e cols. ${ }^{4}$ advertem que o uso de soro fisiológico para preservação de lentes de contato aumenta bastante o risco de contaminação e de infecção. Através do exame dos estojos de conservação de LC, Midelfart e cols. ${ }^{5}$ descobriram que $24 \%$ deles estavam contaminados. Estes resultados tem índice baixo, se comparado com outros estudos, como por exemplo o de Kampolat que encontrou $57 \%$ dos estojos contaminados. Porém, no estudo feito por Midelfart cerca de $80 \%$ dos patógenos poderiam potencialmente causar úlcera de córnea. Em 1995, Lipener e cols. ${ }^{6}$ em um estudo prospectivo, encontrou contaminação em $86 \%$ dos estojos, $80 \%$ das LC e $60 \%$ dos frascos de solução salina usados no enxágüe das lentes; Pseudomonas Aeruginosa e Proteus Mirabilis foram os agentes isolados mais freqüentes. No caso em questão, não houve interesse prático na realização de cultura das lentes e seus acessórios pois tal medida não iria mudar o diagnóstico nem a conduta.

Quando as LC descartáveis chegaram ao mercado há 10 anos, acreditou-se que a incidência de infiltrados infecciosos diminuiria bastante, pois sem a manipulação a contaminação das LC seria reduzida. Os primeiros trabalhos confirmaram as expectativas, sendo o número de úlceras de córnea menor com o uso deste tipo de lente. Porém, não demorou para que casos de úlcera de córnea com LC descartáveis fossem relatados, inclusive por Pseudomonas. Acredita-se que estas foram devidas ao incorreto uso das lentes, por falta de orientação de adaptadores e pacientes ${ }^{7}$.

Stapleton e cols. ${ }^{8}$ ao analisarem os fatores de risco para ceratite supurativa em usuários de LC, concluíram que idade (maiores de 30 anos) e classe econômica alta estão mais relacionados a úlceras estéreis enquanto que o uso prolongado (noturno) está mais relacionado a úlceras microbianas. A qualidade da desinfecção segundo este autor não influi no tipo de ceratite, porém o mesmo ressalta a maior eficiência do peróxido de hidrogênio. Concluiu também que a idade das LC não influencia sobre infecção, sugerindo que a lente descartável não reduz o risco de infecção.

Schein e cols. ${ }^{9}$ analisando o impacto do uso noturno de lentes de contato, estimaram que o risco de ceratite ulcerativa foi de $49 \%$ para uso diário e $74 \%$ para o uso noturno. Poggio e cols. ${ }^{10}$ sugerem que o risco de ceratite supurativa com o uso noturno é de 1 para 160 a 300 indivíduos por ano, enquanto para uso diário é de 1 para 2500 indivíduos por ano.

Suchecki e cols. ${ }^{11}$ em estudo sobre infiltrados periféricos corneanos em usuários de LC verificaram que $40 \%$ destes apareceram em pacientes que faziam uso prolongado de lentes 
descartáveis, seguido por $21 \%$ em uso prolongado das lentes convencionais. O uso diário de lentes descartáveis apresentou a menor porcentagem, $2 \%$. Todos os pacientes com infiltrados periféricos tiveram boa resolução sem complicações.

Poggio e cols., comparam as complicações entre lentes descartáveis em esquema de uso diário e prolongado com lentes gelatinosas convencionais. Verificou que o uso diário de lentes descartáveis tinha prevalência de complicações semelhante ao uso diário das gelatinosas convencionais. Quanto ao uso prolongado, o número de complicações foi significantemente menor quando comparado às lentes convencionais. Observou também que o uso prolongado das descartáveis está mais relacionado aos infiltrados periféricos estéreis enquanto as convencionais estão mais associadas com úlceras microbianas centrais ${ }^{12}$.

Maguen e cols. ${ }^{13}$ acompanharam 100 pacientes usuários de lentes descartáveis em regime de uso prolongado e concluíram que em pacientes bem orientados quanto à forma de uso, com higiene adequada e com boa aderência às recomendações médicas, este tipo de lente é uma boa opção para correção de ametropias. Porém, Kent e cols. ${ }^{14}$ alertam que o uso de LC descartáveis pode estar relacionado com sérias infecções corneanas e relatam 2 casos de úlcera de córnea por Pseudomonas. Como em ambos os casos, a infecção ocorreu em poucos dias de uso, concluiu-se que a exposição ao Pseudomonas ocorreu durante o processo adaptativo. Nos dois casos, a adaptação de lentes de contato não havia sido feita por médicos oftalmologistas. Por outro lado, Killingsworth relatou um caso de úlcera após 3 meses de uso de lente descartável em um paciente que seguia corretamente as orientações prescritas ${ }^{15}$.

$\mathrm{O}$ caso apresentado chama a atenção em relação à literatura por tratar-se de ceratite bilateral por Pseudomonas. Em nosso meio, destaca-se também o fato do paciente ter feito adaptação da LC sem receita e sem exame oftalmológico prévio. Além disso, não fazia a desinfecção e limpeza de maneira regular, alternava uso diário com uso contínuo, sem respeitar os períodos adequados de descanso.

$\mathrm{O}$ aparecimento de casos como este pode sugerir que a venda e o uso indiscriminado de lentes descartáveis, sem exame oftalmológico prévio, acompanhamento contínuo e orientação adequada pode tornar-se de grande risco para a população.

\section{SUMMARY}

Introduction: Although the use of contact lenses is apparently very simple, it is necessary to obey criteria for their correct use, conservation and disposal. Corneal bacterial ulcers are a much-feared complication for users of contact lenses and can be related to various factors such as hygiene, storage and most of all long-term use.

Purpose: To describe a case of bilateral ulcer, caused by Pseudomonas in a patient who was a user of disposable lenses. This study highlights and discusses the importance of prior examination, instruction and adequate supervision. In addition it is emphasized that although the lenses are disposable, they are not free from the possibility of serious complications.

Case Study: A seventeen-year-old student who had used contact lenses for six months without prior examination or medical prescription complained of pain in the left eye. When he was examined, we observed a corneal ulcer infiltrated in the median periphery. Samples were collected and a treatment with fortified eye-drops was started. After eight hours the patient returned now complaining of pain in the right eye which we examined and observed diffuse keratitis with a mucopurulent secretion. The treatment was the same. Laboratory tests revealed Pseudomonas in both eyes and the ailment was healed within a week's treatment without leaving sequelae.

Discussion: The author discuss the factors involved in the occurrence of infectious keratitis in users of contact lenses illustrating that even though disposable lenses are apparently very simple they can cause serious problems. It also demonstrates that the long-term use of contact lenses is considered to be a main risk factor. The description of a case of bilateral keratitis is a warning about the use of this kind of lens without proper orientation and supervision.

Keywords: Corneal ulcer; Contact lens: disposable, bilateral.

\section{REFERÊNCIAS BIBLIOGRÁFICAS}

1. Sven EN, Montan PG. The hospitalized cases of contact lens induced keratitis in Sweden and their relation to lens type and wear schedule: results of a three year retrospective study. CLAO J 1994;20:97-101.

2 .Cohen E, Gonzalez C, et al. Corneal ulcers associated with contact lenses including experience with disposable lenses. CLAO J 1991;17:173-6.

3. Derick R, Kelley C, Gersman M. Contact lens related corneal ulcers at the Ohio State University Hospitals 1983-1987. CLAO J 1989;15:268-70.

4. Kampolat A, Kalayci D, Arman D, Duruk K. Contamination in contact lens care systems. CLAO J 1992;18:105-7.

5. Midelfart J, Midelfart A, Bevanger L. Microbial contamination of contact lens cases among medical students. CLAO J 1996;22:21-4.

6. Lipener $\mathrm{C}$, Nagoya $\mathrm{F}$ et al. Bacterial contamination in soft contact lens wearers. CLAO J 1995;21:122-4.

7. Laibson R, Cohen E, Rajpal R. corneal ulcers related to contact lenses. CLAO J 1993;19:73-7.

8. Stapleton F, Dart J, Minassian D. Risk factors with contact lens related suppurative keratitis. CLAO J 1993;19:204-10.

9. Schein OD, Buehler PO et al. The impact of overnight wear on the risk of contact lens-associated ulcerative keratitis. Arch Ophthalmol 1994;112:186-90.

10. Poggio EC, Glynn ROJ et al. The incidence of ulcerative keratitis among users of daily-wear and extended wear soft contact lenses. N Eng J Med 1989;321:779-83.

11. Suchecki J, Ehlers W, Donshik P. Peripheral corneal infiltrates associated with contact lens wear. CLAO J 1996;22:41-6.

12. Poggio E, Abelson M. Complications and symptoms in disposable extended wear lenses compared with conventional soft daily wear and soft extended wear lenses. CLAO J 1993;19:31-9.

13. Maguen E, Rosner I et al. A retrospective study of disposable extended wear lenses in 100 patients year 3. CLAO J 1994;20:179-82.

14. Kent H, Sanders R et al. Pseudomonas corneal ulcer associated with disposable soft contact lenses. CLAO J 1989;15:264-5.

15. Killingswoth DW, Stern GA. Pseudomonas keratitis associated with the use of disposable soft contact lenses. Arch Ophthalmol 1989;107:795. 